\title{
ANALISIS TEBAL PERKERASAN JALAN RIGID DI KECAMATAN SINAR PENINJAUAN
}

\author{
Rachardi $^{1}$, Reffanda Kurniawan ${ }^{2 *}$ \\ ${ }^{1}$ Konsultan CV. Cahya Berlian Palembang \\ ${ }^{2}$ Prodi Teknik Sipil Fakultas Teknik Universitas PGRI Palembang \\ *Corresponding Author, Email : reffandakurniawan@yahoo.com
}

\begin{abstract}
ABSTRAK
Jalan merupakan akses yang utama dalam mendukung kelancaran transportasi. Untuk itu konstruksi jalan yang baik merupakan prioritas utama. Salah satu upaya yag dilakukan dengan menganalisis Tebal Perkerasan Jalan Rigid di Kecamatan Sinar Peninjauan. Data - data yang di kumpulkan berdasarkan hasil survey dilapangan dengan menghitung volume Lalu Lintas Harian Rata-Rata (LHR), Kapasitas Jalan dan Studi Pustaka, dilakukan tiap satuan per jam untuk tiap-tiap jenis kendaraan dan volume jam sibuk, misalnya jam sibuk pagi,siang,dansore.Dalam pengumpulan data Analisa Tebal Perkerasan Jalan Rigid di Kecamatan Sinar Peninjauan, Berdasarkan jumlah lajur dan jalur jalan yang ada dikawasan studi, tipe jalan 1 jalur 2 lajur 2 arah, lebar jalur efektif 5 meter.Berdasarkan analisa dan pembahasan, didapat data Lalu Lintas Harian Rata-Rata (LHR) dijalan Kecamatan Sinar Peninjauan tahun 2016 adalah 1628 kendaraan/hari/2 jalur 2 arah, tebal perkerasan $18 \mathrm{~cm}$, tulangan memanjang yang dipakai $\emptyset 14-100 \mathrm{~mm}$ untuk tulangan melintang dipakai $\emptyset 12-300 \mathrm{~mm}$. Untuk peningkatan kualitas jalan sebaiknya menggunakan bahan yang memenuhi standar Bina Marga dan dapat menghasilkan jalan yang kuat, nyaman dalam berkendara.
\end{abstract}

Kata Kunci : Analisis, Tebal Perkerasan, Jalan Rigid

\section{PENDAHULUAN}

Kosntruksi perkerasan kaku (Rigid Pavement) banyak digunakan pada kondisi tanah dasar yang mempunyai daya dukung rendah, atau pada kondisi tanah dasar yang mempunyai daya dukung yang tidak seragam kelebihan dari kontruksi perkerasan kaku adalah sifat kekakuanya yang mampu menahan beban roda kendaraan dan menyebarkan ke tanah dasar secara efisien

Selain itu juga sering terjadi kerusakan jalan antara lain karena beban lalu lintas berulang yang berlebihan (overloaded), panas/suhu udara, air dan hujan serta mutu awal produk yang jelek. Oleh sebab itu disamping direncanakan secara tepat jalan harus dipelihara dengan baik agar dapat melayani pertumbuhan lalu lintas selama umur rencana.Pemeliharaan jalan rutin maupun berkala perlu dilakukan untuk mempertahankan keamanan dan kenyamanan jalan bagi pengguna dan menjaga daya tahan/keawetan sampai umur rencana. Khusus jalan Kabupaten di wilayah Kecamatan Sinar Peninjauan Kabupaten OKU kondisinya kini sudah rusak parah, lubang menganga lebar, saat hujan turun menjadi kubangan kerbau, akibatnya sering terjadi kerusakan pada perkerasan jalan fleksibel, dan diberikan solusi dengan mengunakan perkerasanjalan rigid supaya untuk mengurangi kerusakan jalan dan memberikan rasa aman, kuat dan nyaman dalam berkendara. Berdasarkan uraian di atas peneliti tertarik untuk menganalisa tebal perkerasan jalan tersebut dengan standar Bina Marga atau SNI PDT-T-14-2003. 
Permasalahan dalam menganalisa tebal perkerasan jalan rigid pada ruas jalan di Kecamatan Sinar Peninjauan yang di akibatkan kerusakan jalan fleksibel dan diberikan solusi dengan mengganti perkerasan jalan rigid dengan beban kendaraan yang terjadi, agar didapat jalan yang kuat, aman dan nyaman dengan standar Bina Marga. Sedangkan maksud dan tujuan melakukan penelitian ini adalah :

1. Untuk menganalisa tebal perkerasan jalan kaku pada jalan Kecamatan SinarPeninjauan.

2. Untuk mengetahui banyak LHR yang ada di jalan Kecamatan Sinar Peninjauan.

3. Untuk menganalisa kondisi perkerasan jalan rigid dan menghitung lapisan perkerasan kaku yaitu lapisan permukaan, lapisan pondasi atas, dan lapisan pondasi bawah.

Batasan masalah agarAgar dapat memberikan kejelasan dalam penelitian ini sesuai dengan tujuan yang hendak di capai, maka dilakukan pembatasan-pembatasan seperti:

1. Lokasi penelitian Unit XIV - Unit XVI Kecamatan Sinar Peninjauan.

2. Perhitungan perkerasan jalan rigid metode BinaMarga.

3. Jenis jalan rigid pada ruas jalan Kecamatan SinarPeninjauan.

\section{TINJAUAN PUSTAKA}

Perkerasan jalan adalah bagian dari jalur lalu lintas, yang bila kita perhatikan secara struktural pada penampang melintang jalan, merupakan penampang struktur kedudukan paling sentral dalam suatu badan jalan,Nurdin,dkk.1997. Lalu lintas langsung terkosentrasi pada bagian dan boleh di katakan merupakan urat nadi dari seluruh kontruksi jalan. Perkerasan jalan dalam kondisi baik maka arus lalu lintas akan berjalan dengan lancar demikian sebaliknya kalau perkerasan jalan rusak lalu lintas akan terganggu. Menurut Saodang.2005:1, Perkerasan beton semen adalah struktur yang terdiri atas pelat beton semen yang bersambung (tidak menerus) tanpa atau dengan tulangan, atau menerus dengan lapisan permukaan beraspal. Struktur perkerasan beton semen secara tipikal terlihat gambar 1.

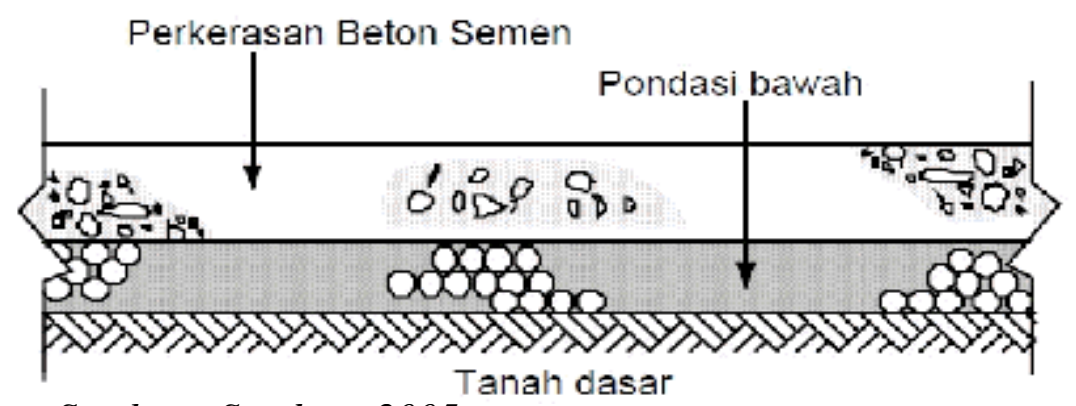

Sumber : Saodang 2005

Gambar 1. Tipikal Struktur Perkerasan Beton Semen.

\section{Komponen Jalan}

Menurut Hendra, S 1994:4, berdasarkan dari kondisi yang ada maka perlu diketahui komponen yang perlu di perhatikan pada suatu jaringan didalam kota, seperti bangunan perlengkapan pada jalan yang sering kita jumpai seperti:

1. Jalur Lalu Lintas 
2. Bahu Jalan

3. Trotoar

4. Median

5. Saluran Samping

6. Kerb

\section{Penyebab Kerusakan Jalan}

Faktor faktor penyebab kerusakan jalan sebagai berikut:

1. Air hujan. Hal ini menjadi salah satu faktor pendukung penyebab kerusakan jalan disaat air hujan turun dan mengalami perhentian pergerakan menuju saluran pembuangan atau yang dinamakan terjadi genangan air dijalan, maka akan terjadi pengeroposan lapisan aspal oleh air karena kita tahu bahan utama penyusun jalan ialah batu pecah dan aspal. Dengan adanya air tadi yang mengakibatkan daya peningkat aspal yang berkurang maka timbulnya lubang kecil.

2. Beban Kendaraan yang melintas. Hal ini berkaitan dengan faktor penyebab nomor 1 karena apabila terbentuknya suatu lubang tersebut kecil tetapi apabila lama kelamaan tekena beban truck yang melintasi diatas jalan maka akan mengakibatkan lubang tersebut yang sudah mengalami pengurangan daya ikat antar partikel dan menerima bebanpartikel.

3. Tanah yang labil.

\section{Lapisan PerkerasanJalan}

Berdasarkan bahan ikat, lapisan perkerasan jalan dibagi atas 2 kategori:

1. Lapisan Perkerasan Lentur (flexible pavement)

Yang dimaksud perkerasan lentur (flexible pavement) adalah perkerasan yang umumnya menggunakan bahan campuran beraspal sebagai lapis permukaan serta bahan berbutir sebagai lapisan di bawahnya. Sehingga lapisan perkerasan tersebut mempunyai flexibilitas/kelenturan yang dapat menciptakan kenyaman kendaraan dalam melintas diatasnya.

Komponen Perkerasan Lentur (Flexible Pavement) terdiri atas:

a. Tanah Dasar (sub grade)

Tanah Dasar adalah permukaan tanah semula atau permukaan galian atau permukaan tanah timbunan, yang dipadatkan dan merupakan permukaan dasar untuk perletakan bagian-bagian perkerasan lainnya.

Kekuatan dan keawetan konstruksi perkerasan jalan sangat tergantung dari sifatsifat dan daya dukung tanah dasar. Umumnya persoalan yang menyangkut tanah dasar adalah sebagai berikut:

- Perubahan bentuk tetap (deformasi permanen) dari macam tanah tertentu akibat beban lalu lintas.

- Sifat mengembang dan menyusut dari tanah tertentu akibat perubahan kadar air.

- Daya dukung tanah yang tidak merata dan sukar ditentukan secara pasti pada daerah dengan macam tanah yang sangat berbeda sifat dan kedudukannya, atau akibat pelaksanaan. 
b. Lapis Pondasi Bawah (sub base course)

Lapis Pondasi Bawah adalah bagian perkerasan yang terletak antara lapis pondasi dan tanah dasar.

Fungsi lapis pondasi bawah antara lain:

- Sebagai bagian dari konstruksi perkerasan untuk mendukung dan menyebarkan beban roda.

- Mencapai efisiensi penggunaan material yang relatif murah agar lapisanlapisan selebihnya dapat dikurangi tebalnya (penghematan biaya konstruksi).

- Untuk mencegah tanah dasar masuk ke dalam lapis pondasi.

- Sebagai lapis pertama agar pelaksanaan dapat berjalan lancar.

Hal ini sehubungan dengan terlalu lemahnya daya dukung tanah dasar terhadap roda-roda alat-alat besar atau karena kondisi lapangan yang memaksa harus segera menutup tanah dasar dari pengaruh cuaca.

Bermacam-macam tipe tanah setempat (CBR > 20\%, PI < 10\%) yang relatif lebih baik dari tanah dasar dapat digunakan sebagai bahan pondasi bawah. Campurancampuran tanah setempat dengan kapur atau semen portland dalam beberapa hal sangat dianjurkan, agar dapat bantuan yang efektif terhadap kestabilan konstruksi perkerasan.

c. Lapis Pondasi (base course)

Lapis Pondasi adalah bagian perkerasan yang terletak antara lapis permukaan dengan lapis pondasi bawah (atau dengan tanah dasar bila tidak menggunakan lapis pondasi bawah).

Fungsi lapis pondasi antara lain:

- Sebagai bagian perkerasan yang menahan beban roda,

- Sebagai perletakan terhadap lapis permukaan.

Bahan-bahan untuk lapis pondasi umumnya harus cukup kuat dan awet sehingga dapat menahan beban-beban roda. Sebelum menentukan suatu bahan untuk digunakan sebagai bahan pondasi, hendaknya dilakukan penyelidikan dan pertimbangan sebaik-baiknya sehubungan dengan persyaratan teknik.

Bermacam-macam bahan alam / bahan setempat (CBR > 50\%, PI < 4\%) dapat digunakan sebagai bahan lapis pondasi, antara lain : batu pecah, kerikil pecah dan stabilisasi tanah dengan semen atau kapur.

d. Lapis Permukaan (surface course)

Lapis Permukaan adalah bagian perkerasan yang paling atas. Fungsi lapis permukaan antara lain:

- Sebagai bahan perkerasan untuk menahan beban roda

- Sebagai lapisan rapat air untuk melindungi badan jalan kerusakan akibat cuaca.

- Sebagai lapisan aus (wearing course).

Bahan untuk lapis permukaan umumnya adalah sama dengan bahan untuk lapis pondasi, dengan persyaratan yang lebih tinggi. Penggunaan bahan aspal diperlukan agar lapisan dapat bersifat kedap air, disamping itu bahan aspal sendiri 
memberikan bantuan tegangan tarik, yang berarti mempertinggi daya dukung lapisan terhadap beban roda lalu lintas.

Pemilihan bahan untuk lapis permukaan perlu dipertimbangkan kegunaan, umur rencana serta pentahapan konstruksi, agar dicapai manfaat yang sebesar-besarnya dari biaya yang dikeluarkan.

Jenis-jenis Lapis Permukaan (surface course) :

- Lapis Aspal Beton (LASTON), adalah merupakan suatu lapisan pada konstruksi jalan yang terdiri dari agregat kasar, agregat halus, filler dan aspal keras, yang dicampur, dihampar dan dipadatkan dalam keadaan panas pada suhu tertentu.

- Lapis Penetrasi Makadam (LAPEN) adalah merupakan suatu lapis perkerasan yang terdiri dari agregat pokok dengan agregat pengunci bergradasi terbuka dan seragam yang diikat oleh aspal keras dengan cara disemprotkan diatasnya dan dipadatkan lapis demi lapis dan apabila akan digunakan sebagai lapis permukaan perlu diberi laburan aspal dengan batu penutup.

- Lapis Asbuton Campuran Dingin (LASBUTAG) adalah campuran yang terdiri dari agregat kasar, agregat halus, asbuton, bahan peremaja dan filler (bila diperlukan) yang dicampur, dihampar dan dipadatkan secara dingin.

- Hot Rolled Asphalt (HRA) merupakan lapis penutup yang terdiri dari campuran antara agregat bergradasi timpang, filler dan aspal keras dengan perbandingan tertentu, yang dicampur dan dipadatkan dalam keadaan panas pada suhu tertentu.

- Laburan Aspal (BURAS) adalah merupakan lapis penutup terdiri dengan ukuran butir maksimum dari lapisan aspal taburan pasir 9,6 mm atau 3/8 inch.

- Laburan Batu Satu Lapis (BURTU) adalah merupakan lapis penutup yang terdiri dari lapisan aspal yang ditaburi dengan satu lapis agregat bergradasi seragam. Tebal maksimum $20 \mathrm{~mm}$.

- Laburan Batu Dua Lapis adalah merupakan lapis penutup yang terdiri dari lapisan aspal ditaburi agregat yang dikerjakan dua kali secara berurutan. Tebal maksimum $35 \mathrm{~mm}$.

- Lapis Aspal Beton Pondasi Atas (LASTON ATAS) adalah merupakan pondasi perkerasan yang terdiri dari campuran agregat dan aspal dengan perbandingan tertentu, dicampur dan dipadatkan dalam keadaan panas.

- Lapis Aspal Beton Pondasi Bawah (LASTON BAWAH) adalah pada umumnya merupakan lapis perkerasan yang terletak antara lapis pondasi dan tanah dasar jalan yang terdiri dari campuran agregat dan aspal dengan perbandingan tertentu dicampur dan dipadatkan pada temperatur tertentu.

- Lapis Tipis Aspal Beton (LATASTON) adalah merupakan lapis penutup yang terdiri dari campuran antara agregat bergradasi timpang, filler dan aspal keras dengan perbandingan tertentu yang dicampur dan dipadatkan dalam keadaan panas pada suhu tertentu. Tebal padat antara 25 sampai $30 \mathrm{~mm}$.

- Lapis Tipis Aspal Pasir (LATASIR) adalah merupakan lapis penutup yang terdiri dari campuran pasir dan aspal keras yang dicampur, dihampar dan dipadatkan dalam keadaan panas pada suhu tertentu. 
- Aspal Makadam adalah merupakan lapis perkerasan yang terdiri dari agregat pokok dan/atau agregat pengunci bergradasi terbuka atau seragam yang dicampur dengan aspal cair, diperam dan dipadatkan secara dingin.

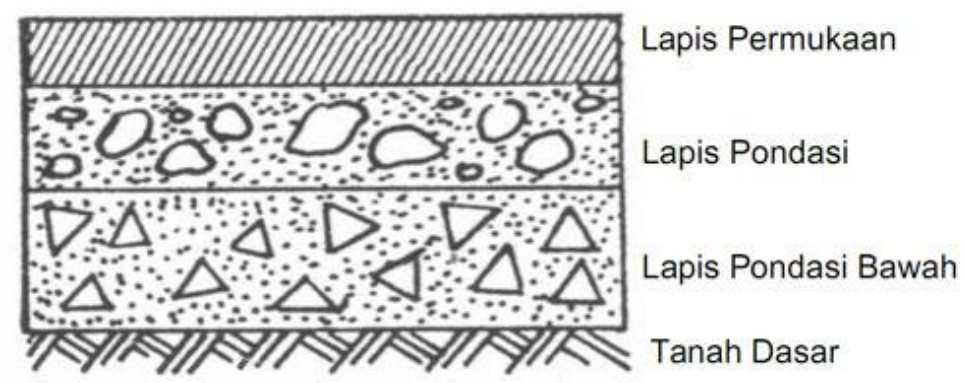

Gambar 2. Perkerasan Lentur (Flexible Pavement).

2. Lapisan Perkerasan Kaku (rigid pavement)

Berdasarkan Perkerasan kaku/Rigid Pavement disebut juga sebagai perkerasan beton semen dimana bahan perkerasan terdiri dari bahan adukan beton, Wignall 2003. Perkerasan kaku cocok digunakan untuk jalan dengan volume lalu lintas tinggi yang di dominasi oleh kendaraan berat di sekitar pintu tol jalan yang melayanikendaraan berat yang melintasi dengan kecepatan rendah, atau di daerah jalan masuk kejalan berkecepatan tinggi yang di dominasi oleh kendaraan berat,Wirahaji,2010.

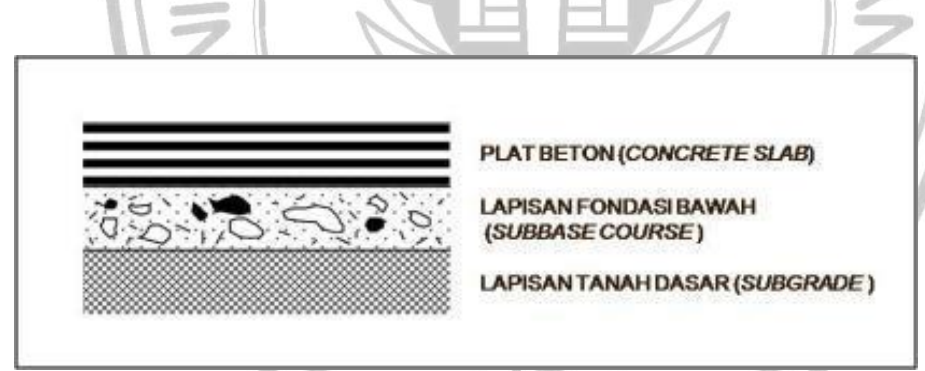

Sumber : Saodang 2005

Gambar 3. Lapisan Perkerasan Rigid (rigid pavement)

Keuntungan menggunakan perkerasan kaku adalah:

1. Umur pelayanan panjang pemeliharaan yang sederhana

2. Durabilitas baik

3. Mampu bertahan pada banjir yang berulang, atau genangan air tanpa terjadinya kerusakan yang berarti.

Kerugian menggunakan perkerasan kaku adalah:

1. Kesehatan jalan kurang baik dan sifat permukaan di pengaruhi oleh proses pelaksanaan

2. Memberikan kesan silau bagi pemakaijalan

3. Membutuhkan lapisan tanah dasar yang memiliki penurunan (settlement) yang homogen agar plat beton tidak retak (Saodang , 2004:60) 
Sifat Umum Perkerasan Kaku

1. Keandalan (serviceability) tinggi mampu memikul bebanbesar

2. Keawetan (durability) lama bisa mencapai umur 30-40tahun

3. Lapisan tunggal (singel layer) dengan LPB tidak terlalustruktual

4. Sangat kaku mudulus elastisitas bisa 25 kali mudulus elastisitas lentur dengan demikian distribusi beban ketanah dasar relatifkecil

5. Kompotitif, karena walaupun biaya awal besar umur rencana lama, dan pemeliharaanringan

6. Dapat digunakan pada tanah dasar dengan daya dukung rendah. Road notw 29, menyebabkan bisa dipakai untuk tanah dasar dengan $\mathrm{CBR}=2 \%-5 \%$.

\section{Beban Lalu LintasRencana}

Berdasarkan secara umum tinjauan lalu lintas rencana akan mengkaji:

1. Jumlah beban sumbu dan kumulatif beban ekivalen yang lewat dan konfigurasi sumbu.

2. Khusus untuk perkerasan kaku beban lalu lintas rencana didapatkan dengan mengakumulasikan jumlah beban sumbu masing masing jenis kelompok, dalam rencana lajur selama perencanaan.

Prosedur yang dilakukan adalah:

1. Hanya mengambil kendaraan niaga dengan berat $\geq 5$ ton

2. Dipilih konfigurasi sumbu

a. STRT (sumbu tunggal roda tunggal)

b. STRG (sumbu tunggal roda ganda)

c. STdRG (sumbu tandem/sumbu ganda roda ganda)

3. Langkah Estimasi Lalu Lintas Rencana

a. Hitung LHR pada akhir usia rencana, sesuai kapasitasjalan

b. Estimasi LHR awal dari kelompok sumbu pada masing masing jenis kelompok sumbu kendaraan niaga ( biasa dibuat kelipatan 0,5 ton, misal $(5-5,5),(5,5-5)$, (6-6,5) demikian seterusnya.

c. Bila ada konversikan beban sumbu tridem ke beban sumbu ganda, yaitu bahwa beban sumbu tridem setara dengan dua sumbu ganda.

d. Hitung KSKN ( jumlah sumbu kendaraan niaga ) selama umur rencana. JSKNUR $=365 \times$ JSKNH X R

Dimana :

JSKNUR = Jumlah total sumbu kendaraan niaga selama umur rencana.

JSKNH = Jumlah total sumbu kendaraan maksimum harian pada saat jalan dibuka.

$\mathrm{R}=$ Faktor pertumbuhan lalu lintas selama umur rencana. 


\section{METODE PENELITIAN}

1. Identifikasi Masalah

2. Pengumpulan Data.

- Data skunder : Gambar Teknik

- Data Primer : Data survey LHR, Panjang Jalan

3. Studi Literatur

4. Survey Lapangan

5. Analisis Data :

Alternatif Solusi (Rigid)

- Analisa Tebal Perkerasan

- Tulangan

- Sambungan Ruji

6. Kesimpulan

\section{DATA DAN ANALISA}

\section{Data Jalan}

Tipe jalan $=1$ Jalur 2 Arah

Jenis agregat

Umur rencana

Dari hasil survei kendaraan yang dilakukan di kecamatan sinar peninjauan selama 3 hari repitisi pertumbuhan lalu lintas per tahun adalah $6 \%$ bisa dilihat di tabel dibawah ini:

Tabel 1. Hasil Survei Data LaluLintas

\begin{tabular}{|l|c|c|}
\hline \multicolumn{1}{|c|}{ Jenis Kendaraan } & $\begin{array}{c}\text { Volume kendaraan } \\
\text { (kend/hari) }\end{array}$ & $\begin{array}{c}\text { Pertumbuhan Lalu } \\
\text { Lintas(\%/thn) }\end{array}$ \\
\hline Kendaraan Ringan 2 ton & 657 & $6 \%$ \\
\hline Truck 2as-6ton & 512 & $6 \%$ \\
\hline Bus 8 ton & 429 & $6 \%$ \\
\hline
\end{tabular}

Dengan Ketentuan:

Kuat Tarik Lentur Beton $\quad=4,25 \mathrm{Mpa}$

Fc KuatTekanBeton $\quad=310 \mathrm{~kg} / \mathrm{cm}^{2}$,slinder)

Bahanpondasi bawah = Stabilitas Semen $12,5 \mathrm{~cm}$ (lihat halaman 29)

Mutu bajatulangan:

- BJTU32 fy = Tegangan Leleh $3200 \mathrm{~kg} / \mathrm{cm}^{2}$

- BJTU24 fy = Tegangan Leleh $2400 \mathrm{~kg} / \mathrm{cm}^{2}$

Antara pelat beton dan lapisan bawah diberi lapisan bound breaker dengan koefisien gesek $\mu=1,5$ 
Menghitung jumlah sumbu kendaraan niaga (JSKN) selama umur rencana:

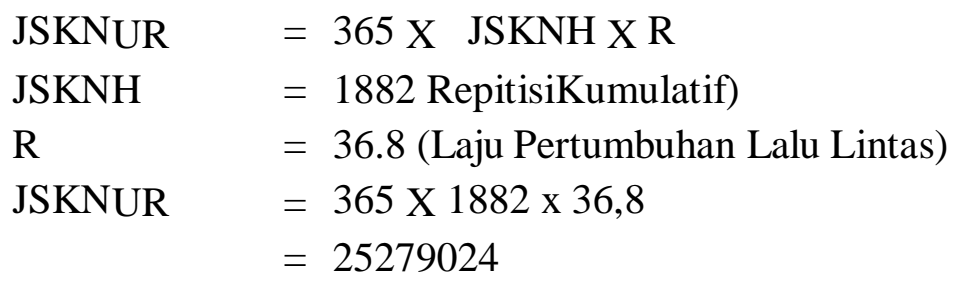

Dari hasil survey kendaraan maka menghitung jumlah repitisi kumulatif tiap kombinasi tiap kombinasi konfigurasi/beban sumbu pada lajur rencana.

Langkah Mencari Jumlah sumbu Kendaraan Niaga :

1. Jumlah Nilai Kendaraan adalah 941 kecuali mobil penumpang,

2. Jumlah sumbu berkendaraan adalah 2

3. Nilai jumlah sumbu kendaraan niaga (JSKNH) yang di dapat $941 \times 2=1882$.

Dari hasil perhitungan di dapat nilai repitisi sumbu rencana $=25279024$.

Menghitung Kekuatan Plat Beton

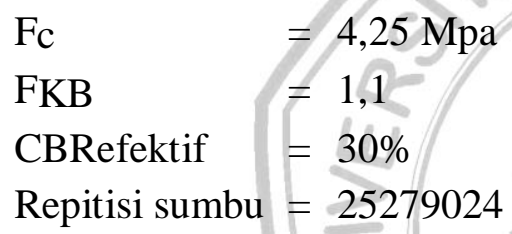

Nilai jumlah sumbu kendaraan niaga $($ JSKN) $=25279024$, Tanpa bahu beton $=1$ tebal. Plat beton nya adalah $18 \mathrm{~cm}$

$\begin{aligned} \text { Tebal Plat Beton } & =180 \mathrm{~mm} \\ \text { LebarPlat } & =2 \times 2.5 \\ \mu & =1.5\end{aligned}$

Angka Ekivalen Baja dan Beton adalah 310 maka di pakai Nilai $\mathrm{N}=6$

$$
\begin{array}{ll}
\text { FCF } & =4.25 \text { Mpa Kuat Tarik LenturBeton } \\
\text { FCT } & =0.5 \times 4.25=2,125 \\
& =21,25 \mathrm{~kg} / \mathrm{m}^{2}
\end{array}
$$

Untuk Baja BJTU 32 Kuat Tarik Leleh: Fy = $320 \mathrm{Mpa}$

Sambungan susut dipasang setiap jarak $=75 \mathrm{~cm}$

Maka Ruji yang digunakan:

$$
\begin{aligned}
& \varnothing \quad=28 \mathrm{~mm} \\
& \text { Panjang } \quad=45 \mathrm{~cm} \\
& \text { Jarak } \quad=30 \mathrm{~cm} \\
& \text { As Perlu } \quad=0,69 \% \times 100 \times 18,0 \\
& =124.55 \mathrm{~cm}^{2} \\
& =1245.5 \mathrm{~mm}^{2} \\
& \text { AsMin } \quad=60 \% \times 100 \times 18,0=10 \mathrm{~cm}^{2}<\text { As perlu }
\end{aligned}
$$

Gunakan tulangan $\varnothing 14 \mathrm{~mm}-100 \mathrm{~mm}\left(\mathrm{As}=1539.4 \mathrm{~mm}^{2}\right)$

Dari perhitungan di atas bahwa tebal plat beton 18 maka di gunakan tulangan memanjang $\varnothing 14 \mathrm{~mm}-100 \mathrm{~mm}$ maka As (luas penampang tulangan baja per meter lebar pelat) $1539.4 \mathrm{~mm}^{2}$. 
Tabel. 2 Rekapitulasi Perhitungan

\begin{tabular}{|c|l|c|c|}
\hline No. & \multicolumn{1}{|c|}{ Keterangan } & Hasil Perhitungan & Hasil Lapangan \\
\hline 1 & Tebal Plat Beton & $\varnothing 18.0 \mathrm{~cm}$ & $20.0 \mathrm{~cm}$ \\
\hline 2 & Tulangan Memanjang & $\varnothing 14-100 \mathrm{~mm}$ & - \\
\hline 3 & Tulangan Melintang & $\varnothing 12-300 \mathrm{~mm}$ & - \\
\hline 4 & Tulangan Ruji & $\varnothing 28 \mathrm{~mm}$ & - \\
\hline
\end{tabular}

Setelah dilakukan perhitungan tulangan baik tulangan memanjang dan melintang maka dapat di gambarkan tanpak atas penulangan dan di dapat hasil perhitungan tulangan memanjang $\varnothing 14 \mathrm{~mm}-100 \mathrm{~mm}\left(\right.$ As $\left.=1539.4 \mathrm{~mm}^{2}\right)$ dan tulangan melintang $\varnothing 12-300 \mathrm{~mm}$ $\left(\right.$ As $\left.=377 \mathrm{~mm}^{2}\right)$ dan diameter tulangan ruji $\varnothing 28 \mathrm{~mm}^{2}$ dari perhitungan tebal perkerasan kaku (Rigid Pavement).

\section{KESIMPULAN}

Kesimpulan yang di ambil dalam analisa tebal perkerasan kaku (rigid pavement) pada ruas jalan di Kecamatan Sinar Peninjauan adalah sebagai berikut:

1. Ruas jalan di kecamatan sinar peninjauan maksimum LHR adalah mobil penumpang 657 , truk 2as-6ton 512, bus 8ton429.

2. Untuk tebal perkerasan di dapat $18 \mathrm{~cm}$ sedangkan di lapangan $20 \mathrm{~cm}$ jadi tebal perkerasan di lapangan memenuhi syarat.

3. Tulangan memanjang di gunakan diameter $14 \mathrm{~mm}$ dengan jarak tulangan $100 \mathrm{~mm}$ sedangkan untuk di lapangan belum diketahui.

4. Tulangan memanjang di gunakan diameter 12 mm dengan jarak/tulangan $100 \mathrm{~mm}$ sedangkan untuk di lapangan belum diketahui.

\section{DAFTAR PUSTAKA}

Saodang, Harmihan, MSCE. IR. 2005." Kontruksi Jalan Raya”. Bandung:Nova.

Sukirman, Silvia. 2010. “Perencanaan Tebal Struktur Perkerasan Lentur”. Bandung: Nova.

Nurdin Muhamad, Mursidi Surahmad IR.” Jurnal Teknik Sipil”. Universitas Negeri Yogyakarta.

Santosa, Wimpy. 1997. Mengenal Sifat Kepekaan Temperatur Aspal. Bandung: FT Univ. Parahyangan

Sukirman, Silvia. 2003. Beton Aspal Campuran Panas. Jakarta: Granit.

Suryadharma, Hendra. 2008. Rekayasa Jalan Raya. Yogyakarta: Univ. Atma Jaya.

Wirahaji. 2010. Beton Aspal-Campuran Panas. Jakarta: Granit.

Wignall, Arthur, dkk. 2003. Proyek Jalan Teori dan Praktek. Edisi ke empat. Jakarta: Erlangga. 